Article

\title{
Structure Manipulation of Carbon Aerogels by Managing Solution Concentration of Precursor and Its Application for $\mathrm{CO}_{2}$ Capture
}

\author{
Pingping He ${ }^{1,2}$, Xingchi Qian ${ }^{1,2}$, Zhaoyang Fei ${ }^{1,2}$, Qing Liu ${ }^{1,3, * \mathbb{D}}$, Zhuxiu Zhang ${ }^{1}$, \\ Xian Chen ${ }^{1}$, Jihai Tang ${ }^{1,2,4}$, Mifen Cui ${ }^{1}$ and Xu Qiao ${ }^{1,2,4, *}$ \\ 1 College of Chemical Engineering, Nanjing Tech University, Nanjing 210009, China; \\ shengrenping@njtech.edu.cn (P.H.); qianxc@njtech.edu.cn (X.Q.); zhaoyangfei@njtech.edu.cn (Z.F.); \\ zhuxiu.zhang@njtech.edu.cn (Z.Z.); chenxian@njtech.edu.cn (X.C.); jhtang@njtech.edu.cn (J.T.); \\ mfcui@njtech.edu.cn (M.C.) \\ 2 State Key Laboratory of Materials-Oriented Chemical Engineering, Nanjing Tech University, \\ Nanjing 210009, China \\ 3 Department of Chemistry Centre for Catalysis Research and Innovation (CCRI), University of Ottawa, \\ Ottawa, ON K1N 6N5, Canada \\ 4 Jiangsu National Synergetic Innovation Center for Advanced Materials (SICAM), Nanjing 210009, China \\ * Correspondence: qing_liu@njtech.edu.cn (Q.L.); qct@njtech.edu.cn (X.Q.); Tel.: +86-25-8358-7168 (Q.L.); \\ +86-25-8317-2298 (X.Q.)
}

Received: 2 February 2018; Accepted: 7 April 2018; Published: 12 April 2018

\begin{abstract}
A series of carbon aerogels were synthesized by polycondensation of resorcinol and formaldehyde, and their structure was adjusted by managing solution concentration of precursors. Carbon aerogels were characterized by X-ray diffraction (XRD), Raman, Fourier transform infrared spectroscopy (FTIR), $\mathrm{N}_{2}$ adsorption/desorption and scanning electron microscope (SEM) technologies. It was found that the pore structure and morphology of carbon aerogels can be efficiently manipulated by managing solution concentration. The relative micropore volume of carbon aerogels, defined by $\mathrm{V}_{\text {micro }} / \mathrm{V}_{\mathrm{tol}}$, first increased and then decreased with the increase of solution concentration, leading to the same trend of $\mathrm{CO}_{2}$ adsorption capacity. Specifically, the CA-45 (the solution concentration of precursors is $45 \mathrm{wt} \%)$ sample had the highest $\mathrm{CO}_{2}$ adsorption capacity $\left(83.71 \mathrm{~cm}^{3} / \mathrm{g}\right)$ and the highest selectivity of $\mathrm{CO}_{2} / \mathrm{N}_{2}(53)$ at 1 bar and $0{ }^{\circ} \mathrm{C}$.
\end{abstract}

Keywords: carbon aerogels; concentration; structure manipulation; $\mathrm{CO}_{2}$ capture

\section{Introduction}

Global climate and eco-environment changes are largely caused by elevated atmospheric $\mathrm{CO}_{2}$ concentration mainly owing to the use of fossil fuels [1]. In order to solve these serious environmental problems, the implementation of carbon capture technologies have been proposed to control $\mathrm{CO}_{2}$ emissions at the existing energy structure [2]. Research on $\mathrm{CO}_{2}$ capture technologies has mainly been performed by using absorption [3], membrane separation [4], adsorption method [5], and so forth.

In absorption, elevated equipment size and corrosion rate, the large energy penalty caused by the regeneration of absorbents are challenging for absorption, especially aqueous amine solutions [6]. Monoethanolamine (MEA) was one of the earliest alkanolamines used for carbon capture, which has a high reaction rate, good absorption capacity. However the major drawbacks such as high energy penalties for regeneration, degradation in oxidizing environment, and corrosive effects limited its application. Membrane separation of $\mathrm{CO}_{2}$ from flue gases depends on the difference in the diffusivity, solubility, absorption and adsorption abilities of different gases on different materials for separation. It was the best 
economical separation technique compared to other separation methods, when a high purity product is not desired [7]. The main limitation in case of membrane separation for carbon capture is need of very high selectivity to extract a relatively low concentration of $\mathrm{CO}_{2}$ from flue gases. Thus, low selectivity is a huge challenge in commercializing this process. Carbon capture by sorbents is much more energy efficient as compared to aqueous amine solutions. Recently, many groups [8] focused on the study of synthetic methods and performance estimations on the new materials, such as metal-organic frameworks (MOFs), porous organic polymers (POPs), zeolites, activated carbons (ACs). Among these materials, porous carbons [9] have been widely researched, which are promising alternatives for $\mathrm{CO}_{2}$ capture by virtue of their high specific surface areas, moderate heat of adsorption, low-cost preparation, relatively easy regeneration, and less sensitivity to the humidity than the other $\mathrm{CO}_{2}$-philic materials.

Porous carbons derived from coal, petroleum and coconut shells have the uncontrollable surface chemistry and pore size due to uncertain structures of various precursors. Recently, carbon aerogels have received an increasing interest for their wide applicability as $\mathrm{CO}_{2}$ adsorbents due to their special pore structure and variable surface properties [10]. Structure manipulation was the important method to enhance $\mathrm{CO}_{2}$ adsorption performance. In addition, the amount of catalyst [11] and doped nitrogen [12] in the preparation process of carbon aerogels were crucial to pore volume and surface defect, thus affecting its $\mathrm{CO}_{2}$ adsorption behavior. Post-modification of carbon aerogels [13] by adding amine was another effective measure to modulate its $\mathrm{CO}_{2}$ adsorption performance. In addition, the preparation of new type carbon aerogel synthesized from bio-based nanocomposites [14] was the hot spot, showing a high $\mathrm{CO}_{2}$ adsorption capacity.

Nowadays, a large number of reports have shown that structure design of the material is crucial to its performance $[15,16]$. It has been widely investigated to regulate the properties of the material simply and effectively. In the preparation process of the material, concentration as a simple yet effective factor for its structure and properties had been extensively studied [17,18]. It was reported by Zhang et al. [19] that the concentration of triphenylene-2,6,10-tricarboxylic acid $\left(\mathrm{H}_{3} \mathrm{TTCA}\right)$ at the liquid-solid interface controlled self-assembling structure to fabricate a chicken-wire porous 2D network, which was confirmed by scanning tunneling microscopic (STM) measurements and density function theory (DFT) calculations. Han et al. [20] discussed the effect of concentration on the lyophilization-induced self-assembly of cellulose particles in aqueous suspensions. They found that cellulose particles self-organized into lamellar structured foam composed of aligned membrane layers with adjustable widths by regulating the concentration. Volpe et al. [21] explored that the concentrations of sodium caseinate (SC) and chitosan $(\mathrm{CH})$ affected the structure and physical properties of the obtained blended films. It was found that the hydrophilic nature of films was reduced by increasing the ratio between $\mathrm{CH}$ and $\mathrm{CS}$.

Carbon aerogels synthesized by using precursors of resorcinol and formaldehyde have been received much attention [22,23]. This paper demonstrates that the structure of carbon aerogel can be managed by solution concentration of its precursors, thus improving its $\mathrm{CO}_{2}$ adsorption performance. Herein, we developed a series of structure-adjustable carbon aerogels by managing the concentration of precursors. The pore structure and surface morphologies of as-prepared sorbents were characterized by X-ray diffraction (XRD), Raman, Fourier transform infrared spectroscopy (FT-IR), $\mathrm{N}_{2}$ adsorption/desorption and scanning electron microscope (SEM) technologies. In addition, adsorption capacity, isosteric heat of adsorption for $\mathrm{CO}_{2}$, selectivity of $\mathrm{CO}_{2} / \mathrm{N}_{2}$, water-resistant performance and adsorption stability of carbon aerogels were investigated to exhibit the adsorption performance of the adsorbents.

\section{Materials and Methods}

All chemicals purchased by Aladdin in this study were of analytical grade and used as received without further purification, as follows: formaldehyde (37-40 wt\% aqueous solution), resorcinol, deionized water, acetone and cetyltrimethyl ammonium bromide.

The preparation process of carbon aerogels was reported elsewhere with some modifications [24]. The molar ratio of cetyltrimethyl ammonium bromide (CTAB), formaldehyde $(F)$ and resorcinol $(R)$ is 
1:125:250, and the solution concentration was controlled as $\mathrm{X} w \mathrm{w} \%$ managing by the amount of water. The solution was under magnetic stirring in a glass vial. Then sealed and made sure that the solution underwent a sol-gel process at $85^{\circ} \mathrm{C}$ for $72 \mathrm{~h}$. Subsequently, the as-prepared organic aerogels were dried at room temperature for $36 \mathrm{~h}$ and then soaked in acetone for $72 \mathrm{~h}$, replacing acetone once a day, finally dried in an oven at $100{ }^{\circ} \mathrm{C}$ at ambient pressure. Afterwards the as-obtained organic aerogels were pre-carbonized at $200^{\circ} \mathrm{C}$ for $2 \mathrm{~h}$ under $\mathrm{N}_{2}$ atmosphere [25]. Then, the pre-carbonized product was carbonized at $900{ }^{\circ} \mathrm{C}$ for $3 \mathrm{~h}$ with a heating rate of $5^{\circ} \mathrm{C} /$ min under $\mathrm{N}_{2}$ atmosphere to get the $\mathrm{CA}-\mathrm{X}$ $(X=25,35,45,55)$ sample.

The phase structure of the CA-X was characterized by powder X-ray diffraction (XRD) on a SarmtLab powder diffractometer using Ni-filtered $\mathrm{Cu} K \alpha$ radiation $(\lambda=0.15406 \mathrm{~nm})$ at a setting of $40 \mathrm{kV}$ and $100 \mathrm{~mA}$. XRD patterns were recorded within the range $10 \sim 80^{\circ}$ at a scan rate of $2^{\circ} / \mathrm{min}$. Raman spectroscopy was measured with spectral resolution of $2 \mathrm{~cm}^{-1}$ in a scanning range of $100-4000 \mathrm{~cm}^{-1}$ on Labram HR800 apparatus (JY Horiba Corporation, Palaiseau, France). In addition, the He-Cd laser at $514 \mathrm{~nm}$ line was used as the excitation source. The surface morphologies of the samples were detected by scanning electron microscope (SEM) at an acceleration voltage of $15 \mathrm{kV}$ on Hitachi S-4800 instrument (FEI, Hillsboro, OR, USA). The Fourier transform infrared (FTIR) spectra were collected on a Nicolit iS50 IR spectrometer (Thermo Nicolet Corporation, Madison, WI, USA) with a DTGS KBr detector (Thermo Nicolet Corporation, Madison, WI, USA) in the range of 4000 to $1000 \mathrm{~cm}^{-1}$ at room temperature. $\mathrm{N}_{2}$-physisorption at $-196^{\circ} \mathrm{C}$ was performed on a BETSORP-II analyzer (MicrotracBEL, Osaka, Japan) to gain the textural properties of the materials. These samples were outgassed at $200{ }^{\circ} \mathrm{C}$ for $2 \mathrm{~h}$ prior to the adsorption measurements. The Brunauer-Emmett-Teller (BET) method was employed to determine the total surface area in the $\mathrm{p} / \mathrm{p}_{0}$ range between 0.05 and 0.20 . The micropore volume was determined by the $\mathrm{t}$-plot method. The mesopore volume and size distribution were calculated from the adsorption branch of the isotherm by the Barrett-Joyner-Halenda (BJH) method.

Static $\mathrm{CO}_{2}$ adsorption experiments were measured by a BELSORP-II adsorption apparatus (MicrotracBEL, Osaka, Japan) at different temperature, which was controlled by a constant temperature water tank. The adsorption isotherms were fitted with the Langmuir model [25] as shown in Equation (1), and isotherm parameters were listed in the Tables S1-S4 at the supporting information.

$$
q=q_{c} \frac{k_{c} p_{t}}{1+k_{c} p_{t}}
$$

where $p$ is the pressure, and $q$ is the adsorption capacity. In addition, $q_{c}$ and $k_{c}$ are the Langmuir model parameters with the subscripts $c$ denoting the channels.

The isosteric heat of adsorption for $\mathrm{CO}_{2}$ over the samples was calculated from the result of three adsorption isotherms at $0,12.5$ and $25^{\circ} \mathrm{C}$ by using the Clausius-Clapeyron equation [25], which was shown in Equation (2). Specifically, the isosteric heat of adsorption was determined by evaluating the slope of the plots of $\ln (P)$ versus $1 / T$ at the same adsorbed amount, where $P$ and $T$ are respectively the absolute pressure and temperature.

$$
\ln \frac{P_{2}}{P_{1}}=\frac{Q}{R}\left(\frac{1}{T_{1}}-\frac{1}{T_{2}}\right)
$$

The selectivity of $\mathrm{CO}_{2} / \mathrm{N}_{2}(15 \% / 85 \%$ in volume) was calculated by using the ideal adsorption solution theory (IAST), which was described particularly in the Appendix A [26].

The test of $\mathrm{CO}_{2}$ breakthrough was measured with a packed-bed column (length $=10.0 \mathrm{~cm}$, inner diameter $=1.0 \mathrm{~cm}$ ) connected to a QGA mass spectrometer (Hiden, Warrington, UK) at the presence of $15 \mathrm{vol} \% \mathrm{CO}_{2}$ with $\mathrm{N}_{2}$ gas. The complete removal of adsorbed species from the adsorbent was achieved through thermal activation at $200{ }^{\circ} \mathrm{C}$ under a purge flow of $\mathrm{N}_{2}$ gas. Besides, in order to determine the effect of water vapor on $\mathrm{CO}_{2}$ adsorption, the $\mathrm{N}_{2}$ gas passed through a water saturator $\left(30^{\circ} \mathrm{C}\right)$ located in a temperature-controlled water bath. 
In addition, the regeneration experiments were also carried out with the BELSORP-II adsorption apparatus. These samples were saturated with $\mathrm{CO}_{2}$ up to 1 bar at $0{ }^{\circ} \mathrm{C}$. In addition the recovered adsorbents were degassed at $100{ }^{\circ} \mathrm{C}$ under vacuum for $30 \mathrm{~min}$ prior to each measurement.

\section{Results and Discussion}

\subsection{Material Characterizations}

\subsubsection{XRD Analysis}

As presented in Figure 1, XRD analysis was carried out to characterize the phase structure of carbon aerogels. The characteristic diffraction peaks around $2 \theta=23^{\circ}$ and $43^{\circ}$ were assigned to the $(002)$ and (101) reflections, which indicated that all carbon aerogels showed short-range-ordered amorphous carbon materials as a partly graphitized carbon according to the reported literatures $[27,28]$. It indicated that the crystal form of the carbon aerogel was hardly affected by the change of solution concentration.

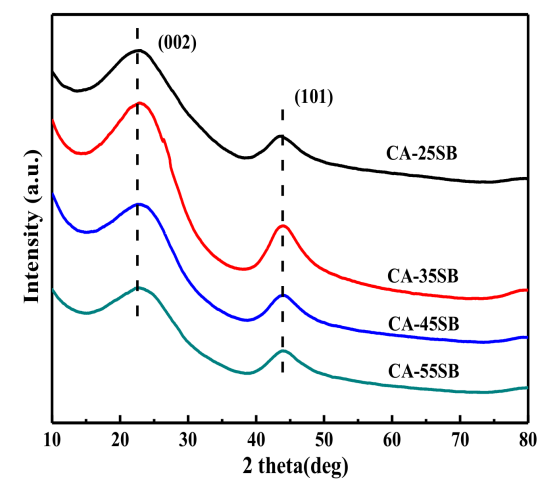

Figure 1. XRD patterns of CA-X samples.

\subsubsection{Raman Analysis}

Raman spectra of the carbon aerogels were employed to further observe the structure and surface defects of carbon aerogels as shown in Figure 2. The Raman spectra of carbon materials were similar to that of the graphite structure. The prominent Raman G-band near $1590 \mathrm{~cm}^{-1}$ was related to the $\mathrm{E}_{2 \mathrm{~g}}$ active modes, which reflected the sp2 type hybridization. In addition, the strong and rather broad D-band, called the defect band, at ca. $1350 \mathrm{~cm}^{-1}$ attributed to a $\mathrm{A}_{1 \mathrm{~g}}$ mode, which assigned to the vibration of carbon atoms with dangling bonds [29]. As expected, the structure of amorphous carbon material as a partly graphitized carbon was formed, which was compatible with the result of XRD analysis. In addition, the relatively adjacent $\mathrm{I}_{\mathrm{D}} / \mathrm{I}_{\mathrm{G}}$ ratio, showing the surface defect of the material, indicated that the change of solution concentration had a little effect on its surface defects.

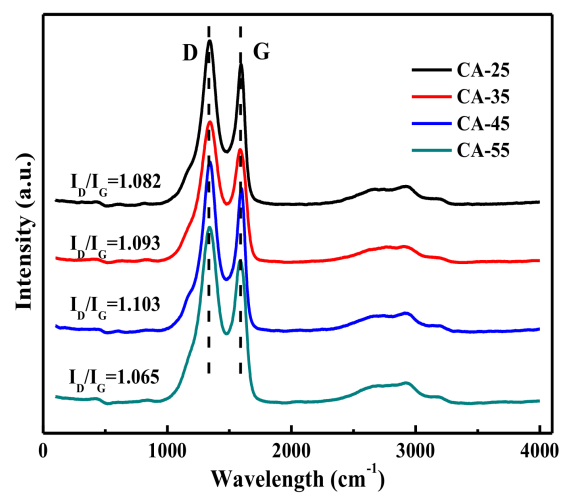

Figure 2. Raman patterns of CA-X samples. 


\subsubsection{FTIR Analysis}

The FTIR spectra of carbon aerogels were exhibited in Figure 3, which were used to detect the surface functional groups of these materials. As shown in the picture, there were no obvious characteristic peak of organic functional groups after the calcination. The typical weak bands at $1570 \mathrm{~cm}^{-1}$ and $1350 \mathrm{~cm}^{-1}$ stem from the absorption peak of carbon in the skeleton over carbon aerogels. And the dominant absorption in the $2800-3000 \mathrm{~cm}^{-1}$ region was an indicative sign of the $\mathrm{C}-\mathrm{H}$ symmetric and asymmetric stretching of $\mathrm{CH}_{2}$ and $\mathrm{CH}_{3}$ groups $[29,30]$. These results forcefully showed that the change of solution concentration can't lead to the variation of surface functional groups.

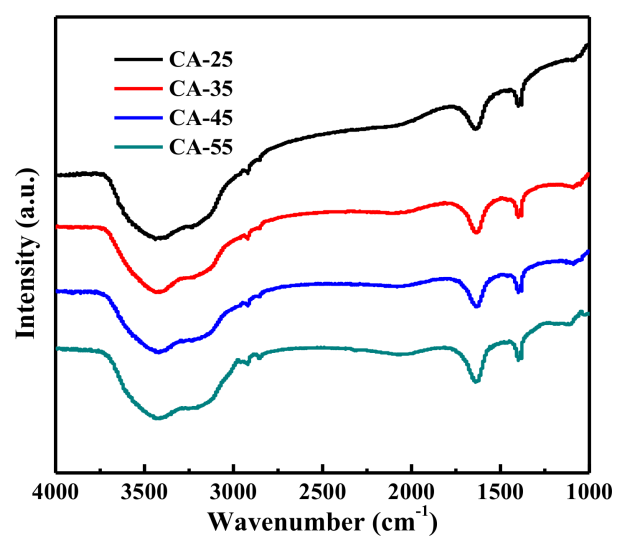

Figure 3. FT-IR spectra of CA-X samples.

\subsubsection{SEM Analysis}

SEM images of these materials were depicted in Figure 4, which were used to investigate the morphologies of carbon aerogels. As shown in the below pictures, it can be seen that the polymerized particle of materials exhibited the special coral shape, which was the typical shape of carbon aerogels. Besides, it can be found that the solution concentration appreciably influenced the size and morphology of carbon aerogel [31]. The size of particle was within the confines of dozens of nanometer caused by the difference of cross-linking strength among clusters, which caused a large number of pores produced between the clusters. Moreover, we can observe that the size of particle became smaller and the degree of cross-linking among clusters was further strengthened as the increase of solution concentration.
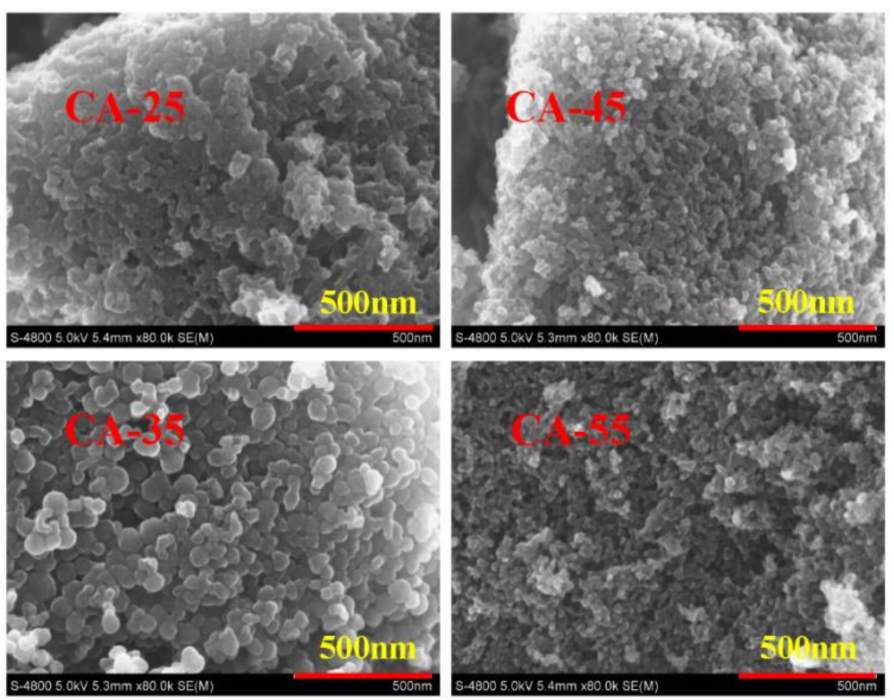

Figure 4. SEM images of CA-X samples. 


\subsection{5. $\mathrm{N}_{2}$ Adsorption/Desorption Analysis}

$\mathrm{N}_{2}$ adsorption/desorption isotherms and BJH pore distribution curves of carbon aerogels were exhibited in Figure 5. As shown in Figure 5a, all materials displayed the typical IV-type isotherm with obvious type $\mathrm{H} 2$ hysteresis loop at $\mathrm{P} / \mathrm{P}_{0}$ range of $0.8 \sim 0.9$, indicating the existence of slit pore structures inside the materials $[25,32]$. It can be indicated that the mesoporous structure of the material was formed by the agglomeration of the nanoparticle building blocks, which was previously confirmed by the SEM observation.

In addition, the textural parameters of samples were listed in Table 1. From the below table, it can be concluded that the CA-45 sample had a specific surface area of $848 \mathrm{~m}^{2} / \mathrm{g}$ and total pore volume of $0.95 \mathrm{~cm}^{3} / \mathrm{g}$. To be specific, the surface area and the ratio of $\mathrm{V}_{\text {micro }} / \mathrm{V}_{\text {tol }}$ firstly enlarged with the increase of the solution concentration, which was probably as the result of the comparatively large pore disappearing that occurred upon the reduction of the water. It was confirmed that the surface area and the ratio of $\mathrm{V}_{\text {micro }} / \mathrm{V}_{\text {tol }}$ decreased as the solution concentration further rising, which was possibly that hypo-water usage was bad for the formation of micropore causing by dispersion of water. Furthermore, the $\mathrm{BJH}$ pore distribution exhibited the opposite rule due to the same reason.
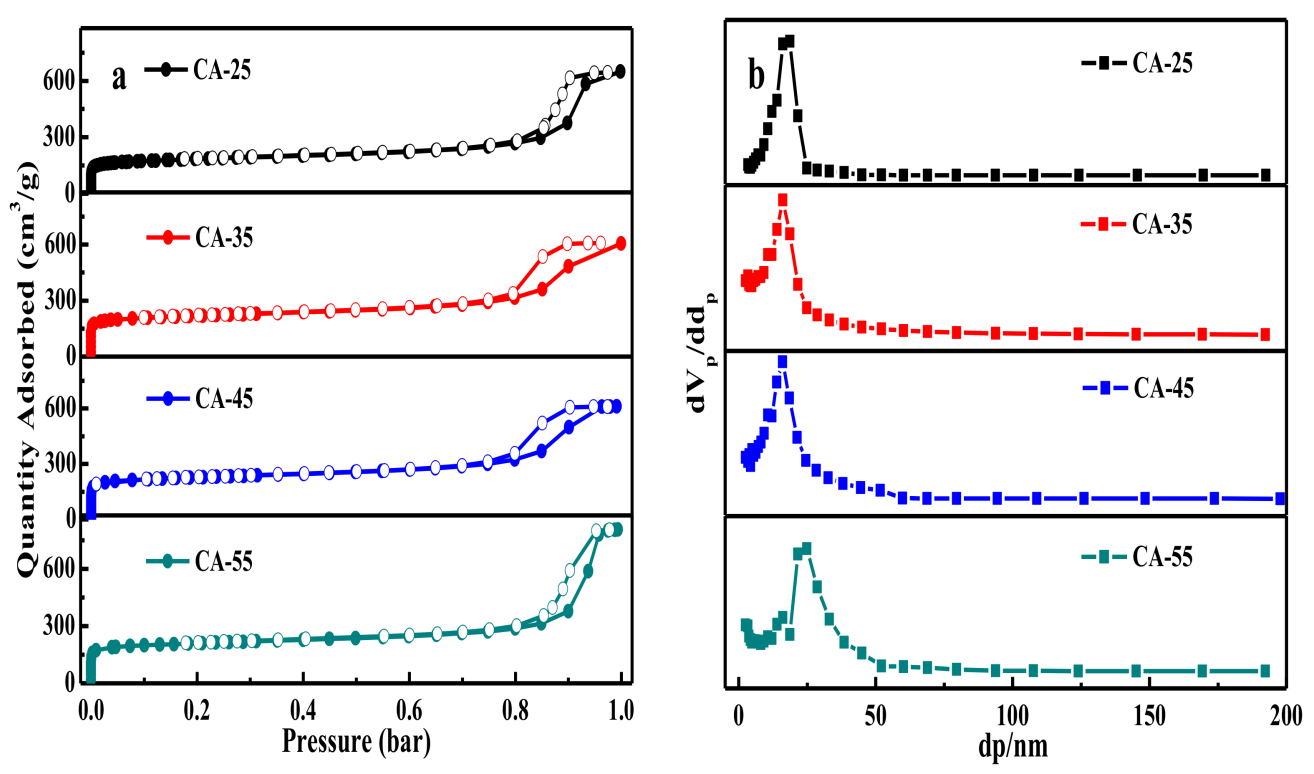

Figure 5. (a) $\mathrm{N}_{2}$ adsorption/desorption isotherms and (b) pore size distributions of CA-X samples.

Table 1. Textural structure parameters of CA-X samples.

\begin{tabular}{|c|c|c|c|c|c|c|}
\hline \multirow{2}{*}{ Sample } & \multirow{2}{*}{$S_{\text {BET }}\left(\mathrm{m}^{2} / \mathrm{g}\right)$} & \multicolumn{3}{|c|}{$V_{p}\left(\mathrm{~cm}^{3} / \mathrm{g}\right)$} & \multirow{2}{*}{$\mathrm{dp}^{2}(\mathrm{~nm})$} & \multirow{2}{*}{$\mathrm{V}_{\text {micro }} / \mathrm{V}_{\text {to }}$} \\
\hline & & Micropore $^{1}$ & Mesopore $^{2}$ & Total & & \\
\hline CA-25 & 638 & 0.20 & 0.79 & 0.99 & 7.37 & 0.20 \\
\hline CA-35 & 813 & 0.25 & 0.67 & 0.92 & 4.52 & 0.27 \\
\hline CA-45 & 848 & 0.27 & 0.68 & 0.95 & 4.46 & 0.28 \\
\hline CA-55 & 784 & 0.24 & 1.00 & 1.24 & 6.34 & 0.19 \\
\hline
\end{tabular}

\section{2. $\mathrm{CO}_{2}$ Adsorption}

\subsection{1. $\mathrm{CO}_{2}$ Adsorption Capacity}

Figure 6 displays the $\mathrm{CO}_{2}$ adsorption isotherms for carbon aerogels at $0,12.5$ and $25^{\circ} \mathrm{C}$, which showed the static adsorption of the materials at different pressure. As shown in Figure 6, we can 
find that the adsorption isotherms of $\mathrm{CO}_{2}$ at 12.5 and $25{ }^{\circ} \mathrm{C}$ for carbon aerogels follow the same law compared to adsorption isotherm at $0{ }^{\circ} \mathrm{C}$. These adsorption isotherms can be well confirmed by the parameters of Langmuir model. Then these parameters were listed in Tables S1-S4 at the supporting information. It was worth noting that the $\mathrm{CO}_{2}$ uptake over carbon aerogels was greatly enhanced as the pressure increasing. $\mathrm{CO}_{2}$ uptake shows the opposite result along with the temperature increasing. With the increase of the solution concentration, the $\mathrm{CO}_{2}$ uptake firstly increased from $68.5 \mathrm{~cm}^{3} / \mathrm{g}$ (CA-25 sample) to $83.7 \mathrm{~cm}^{3} / \mathrm{g}$ (CA-45 sample), then the $\mathrm{CO}_{2}$ uptake over CA-55 sample sharply decreased to $62.7 \mathrm{~cm}^{3} / \mathrm{g}$. On the basis of the aforementioned results, especially pore structure, CA- 45 sample exhibited the highest surface area and ratio of $\mathrm{V}_{\text {micro }} / \mathrm{V}_{\text {tol }}$, which was beneficial to $\mathrm{CO}_{2}$ capture. The adsorption capacities of carbon aerogels had a good correspondence with their surface area, pore volume and pore size. It was worth noting that the $\mathrm{CO}_{2}$ adsorption capacity of CA-45 sample was the highest under the test pressure. The increasing trend of $\mathrm{CO}_{2}$ uptake over carbon aerogels was more obvious at lower relative pressure, which was related to the existence of micropores over the adsorbent. As is well-known that micropores can enhance the contact possibility between $\mathrm{CO}_{2}$ and the pore walls. While the existence of abundant mesopores will provide low-resistant pathways for $\mathrm{CO}_{2}$ through the porous material, which was beneficial to enhance the adsorption performance of the material at higher relative pressure. So the proper value of $\mathrm{V}_{\text {micro }} / \mathrm{V}_{\text {tol }}$, which was defined to weight the value of micropores and mesopores, can improve the $\mathrm{CO}_{2}$ adsorption performance.
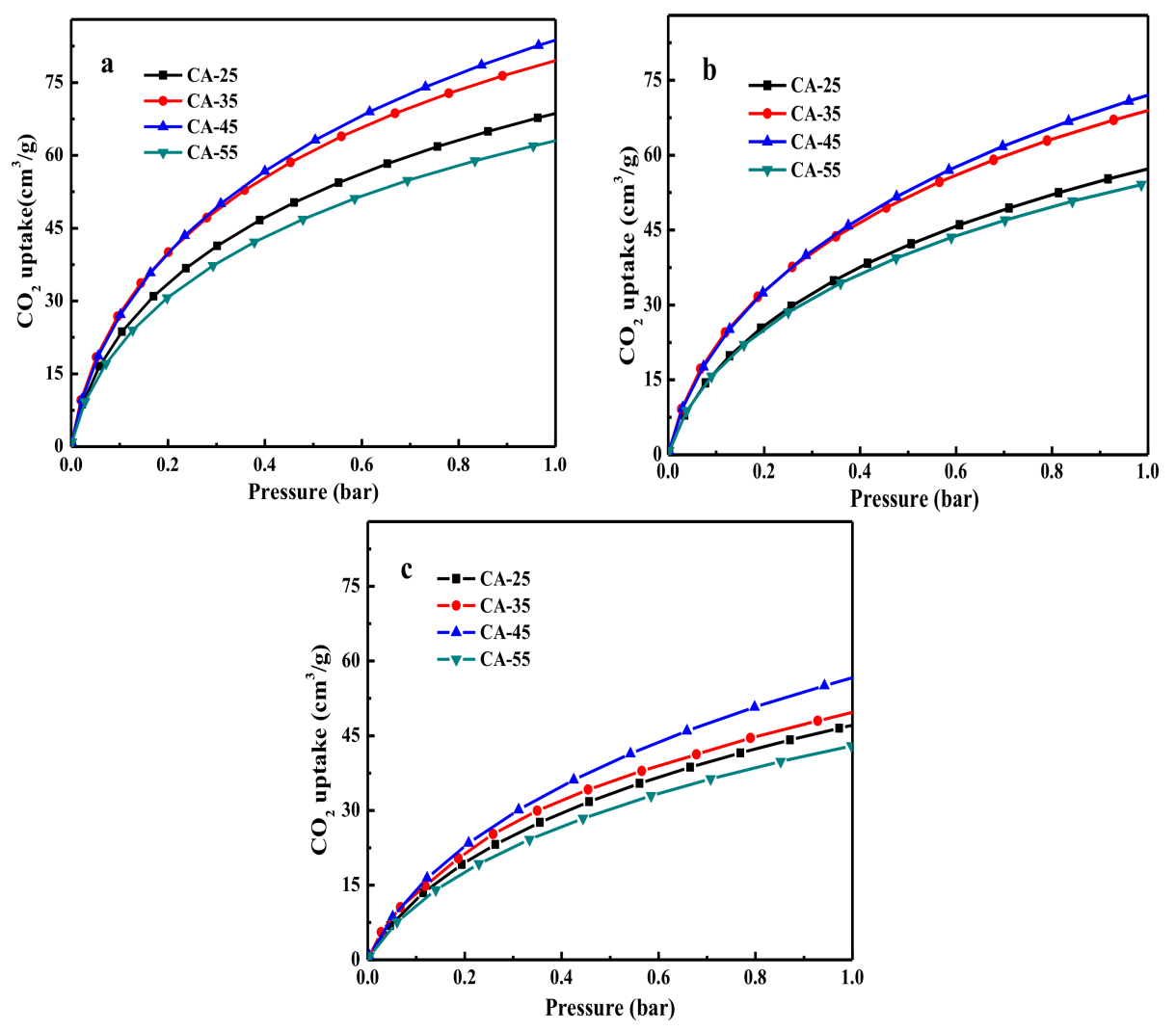

Figure 6. Adsorption isotherms of $\mathrm{CO}_{2}$ at (a) 0 ; (b) 12.5 and (c) $25^{\circ} \mathrm{C}$ over $\mathrm{CA}-\mathrm{X}$ samples.

\subsubsection{Isosteric Heat of Adsorption for $\mathrm{CO}_{2}$}

The estimated isosteric heat of adsorption for $\mathrm{CO}_{2}$ over carbon aerogels was listed at the Table 2 . In order to understand the adsorbate-adsorbent interaction, the isosteric heat of adsorption $\left(\mathrm{Q}_{\mathrm{st}}\right)$ was calculated by using the Clausius-Clapeyron equation from the adsorption isotherms collected at 0 , 12.5 and $25^{\circ} \mathrm{C}$. As displayed in Table 2, the values of adsorption heat were near $25 \mathrm{~kJ} / \mathrm{mol}$, indicating that $\mathrm{CO}_{2}$ adsorption over carbon aerogels was mainly based on physical adsorption caused by the 
channels function. This result was confirmed by the outcomes of Raman which indicated that the change of solution concentration had a little effect on the surface defects. Besides, the low $Q_{\text {st }}$ value was consistent with FTIR analysis which exhibited that changes of concentration can't lead to the variation of surface functional groups. In addition, the relatively low isosteric heat of adsorption for $\mathrm{CO}_{2}$ over the samples had an advantage of low renewable energy consumption.

Table 2. $\mathrm{CO}_{2}$ adsorption capacities of samples under different pressure and operating temperature.

\begin{tabular}{|c|c|c|c|c|c|c|c|c|}
\hline \multirow{3}{*}{ Sample } & \multicolumn{7}{|c|}{$\mathrm{CO}_{2}$ Uptake $\left(\mathrm{cm}^{3} / \mathrm{g}\right)$} & \multirow{3}{*}{$\mathrm{Q}_{\mathrm{st}}{ }^{3}(\mathrm{~kJ} / \mathrm{mol})$} \\
\hline & \multicolumn{2}{|c|}{$0^{\circ} \mathrm{C}$} & \multicolumn{2}{|c|}{$12.5^{\circ} \mathrm{C}$} & \multicolumn{2}{|c|}{$25^{\circ} \mathrm{C}$} & \multirow{2}{*}{$\frac{50{ }^{\circ} \mathrm{C}}{0.15 \text { bar (Humid) }}{ }^{2}$} & \\
\hline & 0.15 bar $^{1}$ & 1 bar $^{1}$ & 0.15 bar $^{1}$ & 1 bar $^{1}$ & 0.15 bar $^{1}$ & 1 bar $^{1}$ & & \\
\hline CA-25 & 28.7 & 68.5 & 22.2 & 57.3 & 16.3 & 47.3 & $13.2(12.1)$ & 25.1 \\
\hline CA-35 & 34.1 & 79.5 & 27.5 & 68.7 & 17.6 & 49.6 & $15.1(14.3)$ & 24.8 \\
\hline CA-45 & 34.2 & 83.7 & 27.6 & 71.8 & 19.1 & 56.5 & $18.5(16.2)$ & 24.3 \\
\hline CA-55 & 26.2 & 62.7 & 22.1 & 54.4 & 14.5 & 43.3 & $13.1(11.9)$ & 25.6 \\
\hline
\end{tabular}

${ }^{1}$ Determined by $\mathrm{CO}_{2}$ adsorption isotherms; ${ }^{2}$ Determined by $\mathrm{CO}_{2}$ breakthrough curves; ${ }^{3}$ Calculated by $\mathrm{CO}_{2}$ adsorption isotherms using the Equation (2).

\subsection{3. $\mathrm{CO}_{2}$ Adsorption Selectivity}

In order to further understand the relationship between structure and $\mathrm{CO}_{2}$ performance, the adsorption isotherms of $\mathrm{N}_{2}$ and $\mathrm{CO}_{2}$ were measured at $0{ }^{\circ} \mathrm{C}$ as shown in Figure S1. All carbon aerogels showed the high uptake of $\mathrm{CO}_{2}$, and $\mathrm{N}_{2}$ uptake was barely adsorbed at $0{ }^{\circ} \mathrm{C}$. For example, the $\mathrm{N}_{2}$ uptake on CA-45 sample was just $13.8 \mathrm{~cm}^{3} / \mathrm{g}$ at $0{ }^{\circ} \mathrm{C}$ and $1 \mathrm{bar}$, which was much lower than the uptake of $\mathrm{CO}_{2}\left(83.7 \mathrm{~cm}^{3} / \mathrm{g}\right)$. Similar results were also observed on other carbon aerogels. The adsorption selectivity of $\mathrm{CO}_{2} / \mathrm{N}_{2}$ was calculated by IAST which has been widely used to predict adsorption selectivity of gas mixtures. In the calculation, the ratio of $\mathrm{CO}_{2} / \mathrm{N}_{2}$ in volume was $15 \% / 85 \%$, which is the typical component of flue gases. Fitting parameters of Langmuir model were listed in Tables S1-S4 at the Supporting Information, and the IAST selectivity results were shown in Figure 7. We can see that the IAST selectivity of $\mathrm{CO}_{2} / \mathrm{N}_{2}$ over carbon aerogels increased with the pressure rising, which was mainly caused by the effect of active adsorption sites on micro- and mesopores. To be specific, the CA-45 sample kept relatively high adsorption selectivity compared to other samples because of the highest relative micropore volume (determined by $\mathrm{V}_{\text {micro }} / \mathrm{V}_{\text {tol }}$ ) and surface area. At a relatively low pressure, the adsorption potential of the mesopore was much lower than that of the micropore. When the pore size of the micropore was close to the size of adsorbate molecules $\left(\mathrm{CO}_{2}\right.$ at $0.33 \mathrm{~nm}$ and $\mathrm{N}_{2}$ at $0.364 \mathrm{~nm}$ ), which caused that $\mathrm{CO}_{2}$ molecules were easier to enter micropores compared to $\mathrm{N}_{2}$. The selectivity of $\mathrm{CO}_{2} / \mathrm{N}_{2}$ on CA-55 sample was 48 at 1 bar, which was the lowest among all samples because that the presence of abundant mesopores provided more adsorbed space to the $\mathrm{N}_{2}$.

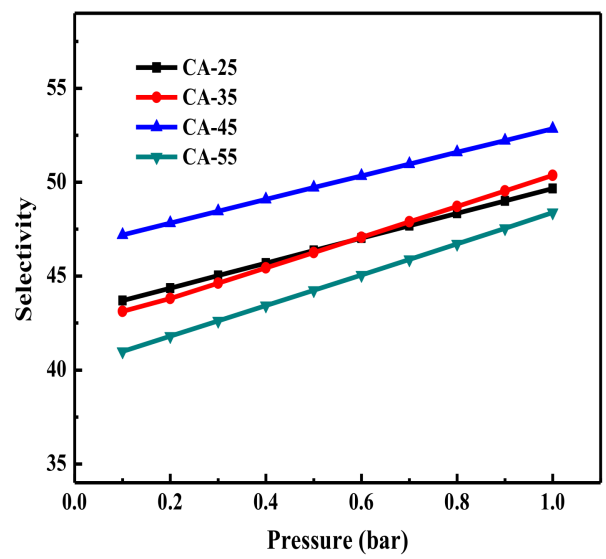

Figure 7. IAST selectivity of $\mathrm{CO}_{2} / \mathrm{N}_{2}\left(15 \% / 85 \%\right.$ in volume) on the CA-X samples at $0{ }^{\circ} \mathrm{C}$. 


\subsubsection{Water-Resistant Experiment}

In order to test the adsorption performance of the materials in flue gases and considering that the flue gases were still warm after $\mathrm{CO}_{2}$ scrubbing $\left(\sim 50{ }^{\circ} \mathrm{C}\right)$, the $\mathrm{CO}_{2}$ breakthrough curves of all samples were measured at $50{ }^{\circ} \mathrm{C}$ in the presence of $15 \mathrm{vol} \% \mathrm{CO}_{2}$ as shown in Figure 8a. The adsorption capacities of carbon aerogels were listed in Table 2. In the table, we can see that the $\mathrm{CO}_{2}$ adsorption capacity of CA-45 sample was $18.5 \mathrm{~cm}^{3} / \mathrm{g}$, respectively. As the flue gases always contain water vapor, it was important to evaluate the effect of moisture on $\mathrm{CO}_{2}$ adsorption performance over the current adsorbents [33]. All samples were also selected to research the effect of water vapor (13.74\%) on $\mathrm{CO}_{2}$ uptake at $50{ }^{\circ} \mathrm{C}$ in the $\mathrm{CO}_{2} / \mathrm{N}_{2}(15 \% / 85 \%$ in volume) mixture to investigate the water-resistant performance of these materials, which was shown in the Figure 8b. Typical $\mathrm{CO}_{2}$ breakthrough curves in the presence of dry and humid gas feed showed that the water vapor had a negative effect on the $\mathrm{CO}_{2}$ adsorption for carbon aerogels. As discussed previously, there was no obvious variation of the adsorption capacity and adsorption rate in the presence of water vapor compared to adsorption behavior on dry gas feed. This is probably attributed to the appropriate relative micropore volume adjusted by managing solution concentration, which was contributed to the fast pathways for $\mathrm{CO}_{2}$ through the porous network at the presence of water vapor.
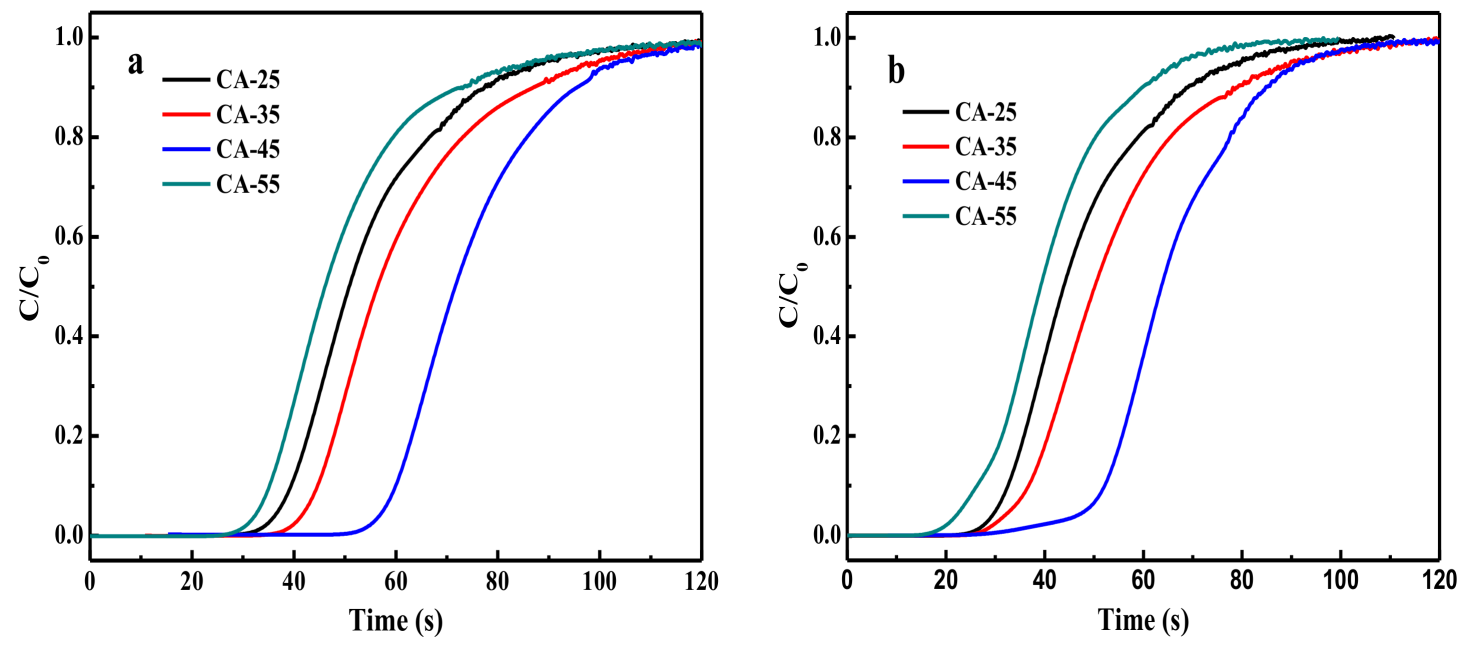

Figure 8. $\mathrm{CO}_{2}$ breakthrough curves of CA-X samples under (a) dry and (b) humid conditions.

\subsubsection{Adsorbent Stability}

Taking account into the practical industrial application, the recyclability of adsorbent is of great significance. Figure 9 summarizes the $\mathrm{CO}_{2}$ adsorption capacity at $0{ }^{\circ} \mathrm{C}$ and recycle times for the entire sorbents. After each adsorption cycle, quite mild conditions (vacuum, $100{ }^{\circ} \mathrm{C}$ and $30 \mathrm{~min}$ ) were executed for the regeneration. No obvious loss of $\mathrm{CO}_{2}$ adsorption capacity (less than $1 \%$ ) on samples took place after several cycles. These sorbents were very stable and exhibited outstanding $\mathrm{CO}_{2}$ adsorption capacities for 6 cycles, which suggests that carbon aerogel is a stable and promising adsorbent for $\mathrm{CO}_{2}$ capture [34]. Excellent recyclability of carbon aerogels should be ascribed to the proper relative micropore volume, which provides a relative loose pathway for $\mathrm{CO}_{2}$ adsorption. 


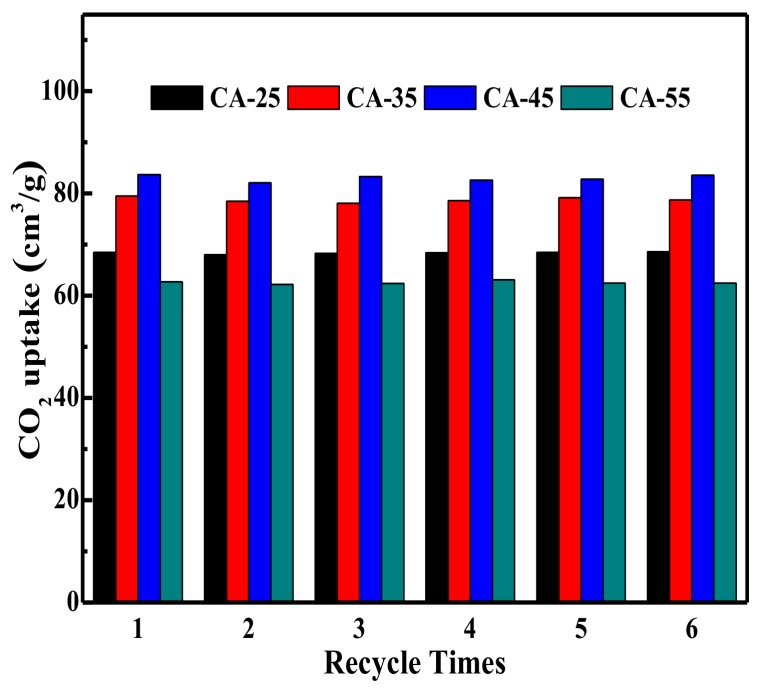

Figure 9. Adsorption isotherms of $\mathrm{CO}_{2}$ over $\mathrm{CA}-\mathrm{X}$ samples at 1 bar and $0{ }^{\circ} \mathrm{C}$.

\section{Conclusions}

In this research, we prepared a series of carbon aerogels synthesized by polycondensation of resorcinol and formaldehyde by managing solution concentration. It was found that the pore structure and morphology of carbon aerogels were influenced by the solution concentration of their precursors. The relative micropore volume (determined by the ratio of $\mathrm{V}_{\text {micro }} / \mathrm{V}_{\text {tol }}$ ) of carbon aerogels was effectively regulated. With the solution concentration increasing, we interestingly found that the particle size decreased and the relative micropore volume was first increasing and then decreasing. The CA- 45 sample had the largest relative micropore volume, which shows the optimum adsorption capacity of $\mathrm{CO}_{2}$ and selectivity of $\mathrm{CO}_{2} / \mathrm{N}_{2}$. At the same time, the phase structure, surface defects and functional groups of carbon aerogels have no obvious difference with the change of solution concentration. The CA- 45 sample exhibited the highest $\mathrm{CO}_{2}$ adsorption capacity up to $83.71 \mathrm{~cm}^{3} / \mathrm{g}$ and highest selectivity of $\mathrm{CO}_{2} / \mathrm{N}_{2}(15 \% / 85 \%$ in volume) (53) at 1 bar, respectively. Moreover, all samples can be completely regenerated under mild conditions, and little loss of $\mathrm{CO}_{2}$ adsorption capacity was detected after six cycles, showing excellent adsorbent stability.

Supplementary Materials: The following are available online at http:/ / www.mdpi.com/2227-9717/6/4/35/s1, Figure S1: Adsorption isotherms of $\mathrm{CO}_{2}$ and $\mathrm{N}_{2}$ over all samples at $0{ }^{\circ} \mathrm{C}$, Tables S1-S4: Fitting parameters derived from isotherms of all samples.

Acknowledgments: This work was supported by National Natural Science Foundation of China (Grant Nos. 21606130, 21306089), the State Key Laboratory of Materials-Oriented Chemical Engineering (Grant ZK201610, ZK201703), and the Priority Academic Program Development of Jiangsu Higher Education Institutions (PAPD).

Author Contributions: Q.L., X.Q. and P.H. conceived and designed these experiments; P.H. and X.Q. performed the experiments and analyzed the data; P.H., X.Q. and Q.L. wrote the paper; Z.F., Z.Z., X.C., J.T., and M.C. supervised the process of experiments and paper.

Conflicts of Interest: The authors declare no conflict of interest.

\section{Appendix A}

The well-known IAST has been extensively reviewed in literature [35] and hence only the working equations will be given here. The theory assumes that the adsorbed phase is an ideal solution of the adsorbed components and the reduced spreading pressure $\left(\pi_{i}^{*}\right)$ of all the components in the mixture in their standard states is equal to the reduced spreading pressure of the adsorbed mixture $\left(\pi^{*}\right)$. Thus,

$$
\pi_{1}^{*}=\pi_{1}^{*}=\cdots=\pi_{n}^{*}=\pi^{*}
$$


The reduced spreading pressure of each component is computed from Gibb's adsorption isotherm as follows:

$$
\pi_{i}^{*}=\frac{\pi_{i} A}{R T} \int_{0}^{P_{i}^{0}} \frac{q_{i}}{P_{i}} d P
$$

Bring Equation (A3) into Equation (1), we can obtain the DL-IAST model. When the gas mixtures achieve balance, the spreading pressures of component $i$ and $j$ are equal. Thus,

$$
q_{c i} \ln \left(1+\frac{k_{c i} y_{i} P_{t}}{x_{i}}\right)-q_{c j} \ln \left[1+\frac{k_{c j}\left(1-y_{i}\right) P_{t}}{1-x_{i}}\right]=0
$$

where $q_{c}$, and $k_{c}$, are the Langmiur model parameters with the subscripts $c$ denoting the channels, respectively. $P_{t}$ is the system pressure, and $q$ is the adsorption amount. What's more, $x_{i}$ and $y_{i}$ are the molar fractions of component $i$ in the adsorbed and bulk phases.

The ideal adsorption solution theory (IAST) has been reported for predicting binary gas mixture adsorption in solid adsorbent. The selectivity of $x_{i}$ over $x_{j}$ has been defined according to Equation (A4). Thus,

$$
S=\frac{\left(x_{i} / y_{i}\right)}{\left(x_{j} / y_{j}\right)}
$$

The adsorbed-phase mole fraction of the different components are related to those of the gas phase by the Raoult's law for ideal solutions, analogous to vapor-liquid systems:

$$
P y_{i}=P_{i}^{0}\left(\pi^{*}\right) x_{i}
$$

With the constraint that

$$
\mathrm{y}_{i}+y_{j}=1 \quad x_{i}+x_{j}=1
$$

So, the selectivity of $\mathrm{CO}_{2} / \mathrm{N}_{2}$ can be calculated as long as the $y_{i}$ is known.

\section{References}

1. Haszeldine, R.S. Carbon Capture and Storage: How Green Can Black Be? Science 2009, 325, 1647-1652. [CrossRef] [PubMed]

2. Boot-Handford, M.E.; Abanades, J.C.; Anthony, E.J.; Blunt, M.J.; Brandani, S.; Mac Dowell, N.; Fernandez, J.R.; Ferrari, M.C.; Gross, R.; Hallett, J.P.; et al. Carbon capture and storage update. Energy Environ. Sci. 2014, 7, 130-189. [CrossRef]

3. Leimbrink, M.; Nikoleit, K.G.; Spitzer, R.; Salmon, S.; Bucholz, T.; Gorak, A.; Skiborowski, M. Enzymatic reactive absorption of $\mathrm{CO}_{2}$ in MDEA by means of an innovative biocatalyst delivery system. Chem. Eng. J. 2018, 334, 1195-1205. [CrossRef]

4. Lu, J.G.; Ge, H.; Chen, Y.; Ren, R.T.; Xu, Y.; Zhao, Y.X.; Zhao, X.; Qian, $\mathrm{H} . ~ \mathrm{CO}_{2}$ capture using a functional protic ionic liquid by membrane absorption. J. Energy Inst. 2017, 90, 933-940. [CrossRef]

5. Puthiaraj, P.; Lee, Y.R.; Ahn, W.S. Microporous amine-functionalized aromatic polymers and their carbonized products for $\mathrm{CO}_{2}$ adsorption. Chem. Eng. J. 2017, 319, 65-74. [CrossRef]

6. Pires, J.C.M.; Martins, F.G.; Alvim-Ferraz, M.C.M.; Simoes, M. Recent developments on carbon capture and storage: An overview. Chem. Eng. Res. Des. 2011, 89, 1446-1460. [CrossRef]

7. Merkel, T.C.; Lin, H.Q.; Wei, X.T.; Baker, R. Power plant post-combustion carbon dioxide capture: An opportunity for membranes. J. Membr. Sci. 2010, 359, 126-139. [CrossRef]

8. Younas, M.; Sohail, M.; Kong, L.L.; Bashir, M.J.; Sethupathi, S. Feasibility of $\mathrm{CO}_{2}$ adsorption by solid adsorbents: A review on low-temperature systems. Int. J. Environ. Sci. Technol. 2016, 13, 1839-1860. [CrossRef]

9. Rashidi, N.A.; Yusup, S. An overview of activated carbons utilization for the post-combustion carbon dioxide capture. J. $\mathrm{CO}_{2}$ Util. 2016, 13, 1-16. [CrossRef]

10. $\mathrm{Wu}, \mathrm{X} . \mathrm{B}$; $\mathrm{Wu}, \mathrm{D} . \mathrm{C}$; $\mathrm{Fu}, \mathrm{R} . W$. Studies on the adsorption of reactive brilliant red X-3B dye on organic and carbon aerogels. J. Hazard. Mater. 2007, 147, 1028-1036. [CrossRef] [PubMed] 
11. Liu, Q.; He, P.P.; Qian, X.C.; Fei, Z.Y.; Zhang, Z.X.; Chen, X.; Tang, J.H.; Cui, M.F.; Qiao, X. Carbon Aerogels Synthesizd with Cetyltrimethyl Ammonium Bromide (CTAB) as a Catalyst and its Application for $\mathrm{CO}_{2}$ Capture. Z. Anorg. Allg. Chem. 2017, 644, 155-160. [CrossRef]

12. Jeon, D.H.; Min, B.G.; Oh, J.G.; Nah, C.; Park, S.J. Influence of Nitrogen moieties on $\mathrm{CO}_{2}$ capture of Carbon Aerogel. Carbon Lett. 2015, 16, 57-61. [CrossRef]

13. Kong, Y.; Jiang, G.D.; Wu, Y.; Cui, S.; Shen, X.D. Amine hybrid aerogel for high-efficiency $\mathrm{CO}_{2}$ capture: Effect of amine loading and $\mathrm{CO}_{2}$ concentration. Chem. Eng. J. 2016, 306, 362-368. [CrossRef]

14. Alhwaige, A.A.; Ishida, H.; Qutubuddin, S. Carbon Aerogels with Excellent $\mathrm{CO}_{2}$ Adsorption Capacity Synthesized from Clay-Reinforced Biobased Chitosan-Polybenzoxazine Nanocomposites. ACS Sustain. Chem. Eng. 2016, 4, 1286-1295. [CrossRef]

15. Li, Z.N.; Gadipelli, S.; Yang, Y.C.; Guo, Z.X. Design of 3D Graphene-Oxide Spheres and Their Derived Hierarchical Porous Structures for High Performance Supercapacitors. Small 2017, 13. [CrossRef] [PubMed]

16. Zhang, C.; He, Y.W.; Mu, P.; Wang, X.; He, Q.; Chen, Y.; Zeng, J.H.; Wang, F.; Xu, Y.H.; Jiang, J.X. Toward High Performance Thiophene-Containing Conjugated Microporous Polymer Anodes for Lithium-Ion Batteries through Structure Design. Adv. Funct. Mater. 2018, 28. [CrossRef]

17. Ahmadi, H.; Lotfollahi-Yaghin, M.A. Stress concentration due to in-plane bending (IPB) loads in ring-stiffened tubular KT-joints of offshore structures: Parametric study and design formulation. Appl. Ocean Res. 2015, 51, 54-66. [CrossRef]

18. Oh, T.H.; Oh, S.K.; Kim, H.; Lee, K.; Lee, J.M. Conceptual Design of an Energy-Efficient Process for Separating Aromatic Compounds from Naphtha with a High Concentration of Aromatic Compounds Using 4-Methyl-N-butylpyridinium Tetrafluoroborate Ionic Liquid. Ind. Eng. Chem. Res. 2017, 56, 7273-7284. [CrossRef]

19. Zhang, S.Q.; Zhang, J.Y.; Deng, K.; Xie, J.L.; Duan, W.B.; Zeng, Q.D. Solution concentration controlled self-assembling structure with host-guest recognition at the liquid-solid interface. Phys. Chem. Chem. Phys. 2015, 17, 24462-24467. [CrossRef] [PubMed]

20. Han, J.Q.; Zhou, C.J.; Wu, Y.Q.; Liu, F.Y.; Wu, Q.L. Self-Assembling Behavior of Cellulose Nanoparticles during Freeze-Drying: Effect of Suspension Concentration, Particle Size, Crystal Structure, and Surface Charge. Biomacromolecules 2013, 14, 1529-1540. [CrossRef] [PubMed]

21. Volpe, S.; Cavella, S.; Masi, P.; Torrieri, E. Effect of solid concentration on structure and properties of chitosan-caseinate blend films. Food Packag. Shelf Life 2017, 13, 76-84. [CrossRef]

22. Aegerter, M.A.; Leventis, N.; Koebel, M.M. Aerogels Handbook; Springer: New York, NY, USA, 2011; pp. 215-233.

23. Far, H.M.; Donthula, S.; Taghvaee, T.; Saeed, A.M.; Garr, Z.; Sotiriou-Leventis, C.; Leventis, N. Air-oxidation of phenolic resin aerogels: Backbone reorganization, formation of ring-fused pyrylium cations, and the effect on microporous carbons with enhanced surface areas. RSC Adv. 2017, 7, 51104-51120. [CrossRef]

24. Li, C.F.; Yang, X.Q.; Zhang, G.Q. Mesopore-dominant activated carbon aerogels with high surface area for electric double-layer capacitor application. Mater. Lett. 2015, 161, 538-541. [CrossRef]

25. Kou, J.H.; Sun, L.B. Nitrogen-Doped Porous Carbons Derived from Carbonization of a Nitrogen-Containing Polymer: Efficient Adsorbents for Selective $\mathrm{CO}_{2}$ Capture. Ind. Eng. Chem. Res. 2016, 55, 10916-10925. [CrossRef]

26. Liu, Q.; He, P.P.; Qian, X.C.; Fei, Z.Y.; Zhang, Z.X.; Chen, X.; Tang, J.H.; Cui, M.F.; Qiao, X.; Shi, Y. Enhanced $\mathrm{CO}_{2}$ Adsorption Performance on Hierarchical Porous ZSM-5 Zeolite. Energy Fuels 2017, 31, 13933-13941. [CrossRef]

27. Jiang, S.F.; Zhang, Z.A.; Qu, Y.H.; Wang, X.W.; Li, Q.; Lai, Y.Q.; Li, J. Activated carbon aerogels with high bimodal porosity for lithium/sulfur batteries. J. Solid State Electrochem. 2014, 18, 545-551. [CrossRef]

28. Lee, Y.J.; Park, H.W.; Park, S.; Song, I.K. Electrochemical properties of Mn-doped activated carbon aerogel as electrode material for supercapacitor. Curr. Appl. Phys. 2012, 12, 233-237. [CrossRef]

29. Patole, A.S.; Patole, S.P.; Kang, H.; Yoo, J.B.; Kim, T.H.; Ahn, J.H. A facile approach to the fabrication of graphene/polystyrene nanocomposite by in situ microemulsion polymerization. J. Colloid Interface Sci. 2010, 350, 530-537. [CrossRef] [PubMed]

30. Patole, A.S.; Patole, S.P.; Jung, S.Y.; Yoo, J.B.; An, J.H.; Kim, T.H. Self assembled graphene/carbon nanotube/polystyrene hybrid nanocomposite by in situ microemulsion polymerization. Eur. Polym. J. 2012, 48, 252-259. [CrossRef] 
31. Nallusamy, S. Synthesis and Characterization of Carbon Black-Halloysite Nanotube Hybrid Composites Using XRD and SEM. J. Nano Res. 2017, 45, 208-217. [CrossRef]

32. Zhuo, H.; Hu, Y.J.; Tong, X.; Zhong, L.X.; Peng, X.W.; Sun, R.C. Sustainable hierarchical porous carbon aerogel from cellulose for high-performance supercapacitor and $\mathrm{CO}_{2}$ capture. Ind. Crop. Prod. 2016, 87, 229-235. [CrossRef]

33. Sayari, A.; Liu, Q.; Mishra, P. Enhanced Adsorption Efficiency through Materials Design for Direct Air Capture over Supported Polyethylenimine. Chemsuschem 2016, 9, 2796-2803. [CrossRef] [PubMed]

34. Qian, Y.; Delgado, J.D.L.P.; Veneman, R.; Brilman, D.W.F. Stability of a Benzyl Amine Based $\mathrm{CO}_{2} \mathrm{Capture}$ Adsorbent in View of Regeneration Strategies. Ind. Eng. Chem. Res. 2017, 56, 3259-3269. [CrossRef]

35. Jiang, W.J.; Yin, Y.; Liu, X.Q.; Yin, X.Q.; Shi, Y.Q.; Sun, L.B. Fabrication of supported cuprous sites at low temperatures: An efficient, controllable strategy using vapor-induced reduction. J. Am. Chem. Soc. 2013, 135, 8137-8140. [CrossRef] [PubMed]

(C) 2018 by the authors. Licensee MDPI, Basel, Switzerland. This article is an open access article distributed under the terms and conditions of the Creative Commons Attribution (CC BY) license (http:/ / creativecommons.org/licenses/by/4.0/). 